\title{
Homeobox B2 is a potential prognostic biomarker of glioblastoma
}

\author{
(iD) Ming Li \\ (D) iu-Fei Wang $^{1}$ \\ (iD) Bo Liu' \\ Diao-Min Wang ${ }^{1}$
}

1. Department of Neurosurgery, Daqing Oilfield General Hospital, Daqing, Heilongjiang 163000 China.

http://dx.doi.org/10.1590/1806-9282.66.6.794

SUMMARY

OBJECTIVES: HOXB2 is a new prognostic indicator for lung cancer. But it is unclear whether HOXB2 holds an effect in glioblastoma (GBM) progression. The purpose of this article was to probe the influences of HOXB2 on GBM pathogenesis.

METHODS: HOXB2 expression level and prognostic power in GBM patients were analyzed. Then the mRNA and protein expression levels of HOXB2 in GBM cell lines were tested by qRT-PCR and western blotting. Cell proliferation, invasion, and migration were determined by CCK8 and transwell assay, severally. The protein levels of PI3K/AKT-pathway associated proteins were analyzed by western blotting.

RESULTS: The results indicated that HOXB2 was distinctly overexpressed in GBM patients and high expression of HOXB2 was related to a poor prognosis. Moreover, the expression of HOXB2 was higher in all GBM cell lines U257, U-87MG, GOS-3 than that in HEB cells (normal control). Meanwhile, decreased expression of P-PI3K and p-AKT were identified after HOXB2 knockdown.

CONCLUSIONS: These data demonstrated that HOXB2 had a vital role in GBM progression and could serve as a promising target for GBM treatment.

KEYWORDS: Glioblastoma. Biomarkers. Homeodomain proteins.

\section{INTRODUCTION}

Glioblastoma (GBM) is the most prevalent and aggressive malignant brain cancer ${ }^{1}$. Currently, the standard treatment methods are surgery, chemotherapy, and radiation therapy ${ }^{2}$. A recent study found that surgical resection extent in elderly patients with glioblastoma has an impact on survival ${ }^{3}$. In recent years, researchers have been working to explore the molecular mechanisms of gliomas, discovering telomerase reverse transcriptase and many other molecules ${ }^{4,5}$. The homeobox (HOX) genes, containing a 183-nucleotide sequence, are a regulated gene family that encodes particular nuclear proteins into transcription factors ${ }^{6}$. The HOX genes contribute to the assignment of segmental identity in the development of hindbrain ${ }^{7}$. In humans, there are four clusters, i.e., HOXA, HOXB, HOXC, and HOXD, which are organized by 39 HOX genes ${ }^{8}$. One piece of evidence revealed that the expression of ectopic HOXB2 in pancreatic cancer may be related to a poor prognosis 9 . However, there were few reports on GBM.

In the present review, we verified the role of HOXB2 in GBM from the following aspects: i) Differential gene analysis and prognosis analysis; ii) the effect of HOXB2 on GBM proliferation, invasion, and 
migration; iii) Study on the mechanism of HOXB2 on phenotype.

\section{METHODS}

Analyses of HOXB2 expression profile from ONCOMINE

In this paper, the expression data of GBM patients and healthy individuals were obtained from the ONCOMINE (https://www.oncomine.org/resource/ login.html) database. According to the median expression value of HOXB2, GBM patients were distributed into high and low expression groups. The statistical significance was determined by the log-rank test.

\section{Culture of GBM cell lines}

Human GBM cell lines U251, U-87MG, GOS-3 and normal human astrocytes HEB were obtained from ATCC (MD, USA). The cells were routinely cultured in RPMI-1640 medium supplemented with FBS (10\%), penicillin $(100 \mathrm{U} / \mathrm{ml})$, and streptomycin $(0.1 \mathrm{mg} / \mathrm{ml})$ with $5 \% \mathrm{CO}_{2}$ at $37^{\circ} \mathrm{C}$.

\section{Cell transfection}

RNA interference was utilized to silence HOXB2 expression in U251 cells. The scrambled siRNA was used as a negative control. Full-length sequences of HOXB2 were cloned into the pcDNA3.1 vector to over-express the HOXB2 level, termed pcDNA3.1-HOXB2 and the negative control pcDNA3.1 were used to over-express HOXB2 expression in GSO-3 cells. si-HOXB2\#1, si-HOXB2\#2, si-control, pcDNA3.1-HOXB2, and pcDNA3.1 were all synthesized by Shanghai GenePharma Co., Ltd. (Shanghai, China) and transfected into human clone cancer cells according to the Lipofectamine2000 transfection kit (Invitrogen, Shanghai, China). The siRNA sequences for HOXB2 were the following.

si-control: F: 5'-AATTCTCCGAACG GTCACGT-3' si-HOXB2\#1: F: 5'-TACTGAATTAGCGTTTAATC-3' si-HOXB2\#2: F: 5'-CAATCAAGGAGTCGACATTA-3'

\section{qRT-PCR}

The extraction of total RNA was carried out with an RNA extraction kit following its instructions. After reverse transcription into cDNA, the expression of HOXB2 was detected by qRT-PCR. Actin was utilized as an internal control. PCR reaction system: $95{ }^{\circ} \mathrm{C}$ for 5 min, 40 cycles of $95{ }^{\circ} \mathrm{C}$ for $30 \mathrm{sec}, 60^{\circ} \mathrm{C}$ for $45 \mathrm{sec}$, and annealing at $72^{\circ} \mathrm{C}$ for $30 \mathrm{~min}$. There were 3 sets of holes in each group. The HOXB2 expression level was calculated by the $2^{-} \Delta \Delta^{\mathrm{ct}}$ method. This was repeated three times independently. The primer sequence was as follows:

\section{HOXB2: F: 5' CGCGAGATGGAAGGAGAGTC 3' R: 5' AGGGCCTGTCTAGTCCTCTG 3' ACTIN: F: 5'CCCGAGCCGTGTTTCCT 3' R: 5' GTCCCAGTTGGTGACGATGC 3'}

\section{CCK8}

To measure cell proliferation, the number of viable cells at $0,24,48$, and $72 \mathrm{~h}$ after transfection was assessed by Cell Counting Kit 8 (CCK8; Dojindo Laboratories, Kumamoto, Japan). The $\mathrm{OD}_{450}$ value was measured by a microplate reader (Bio-Rad, CA, USA) and the proliferation curve was drawn by GraphPad Prism 7.0.

Transwell migration and invasion experiments

Transwell migration and invasion assays were conducted in 24-well Transwell chambers. The upper surface of transwell was precoated with (invasion assay) or without (migration assay) Matrigel (BD Transduction). The transfectants $\left(1 \times 10^{5}\right.$ cells per well) were transferred into the upper chamber. In the lower chamber of 24-well plates, $500 \mu \mathrm{l}$ of complete medium was added. Following $22 \mathrm{~h}$ of incubation, the migrated or invasive cells on the lower surface of the filters were fixed and stained with $0.1 \%$ crystal violet for twenty minutes. After being washed by PBS, the outcomes were photographed under the microscope (Olympus, Tokyo, Japan) and 5 fields of view were randomly selected. The stained cells were counted directly in triplicate.

\section{Western blotting}

Cells were directly lysed in RIPA lysis buffer (Thermo Scientific, Waltham, MA, USA). We used 10\% SDS-PAGE, and $20 \mathrm{\mu g}$ protein were separated. Then the proteins were transferred onto a PVDF membrane. After being enclosed with 5\% non-fat milk at room temperature for one hour, the membrane was then hatched with the primary antibodies at $4^{\circ} \mathrm{C}$ overnight and the secondary antibodies at $37^{\circ} \mathrm{C}$ for two hours. Finally, the membrane was visualized by ECL. QUANTITY ONE software to scan the gray value and Tubulin was employed as an internal control. 


\section{Data statistics}

The outcomes were presented as mean $\pm \mathrm{SD}$. All data analyses were executed utilizing SPSS 22.0 software, and all histograms were drawn employing GraphPad Prism version 7.0. Intergroup differences were assessed by Student's t-tests (between two groups) or analysis of variance (between more than two groups), as appropriate. Post hoc analysis was executed utilizing the Bonferroni test. The outcomes were considered as statistically significant when at $\mathrm{P}<0.01$.

\section{RESULTS}

Increased HOXB2 was discovered in GBM tissues and related to worse prognosis in GBM patients

In the paper, HOXB2 expression in GBM and normal tissues was investigated using the ONCOMINE database. The results indicated that HOXB2 was visibly up-regulated in GBM tissues compared with normal tissues (Figure 1a, $\mathrm{P}=2.93 \mathrm{E}-9$; Figure 1b, $\mathrm{P}=$ 3.31E-9). Besides, based on the TCGA database, the expression of HOXB2 in GBM patients was drawn utilizing GEPIA. According to the median value of HOXB2 expression, patients were distributed into high and low expression groups. GBM patients with HOXB2 high expression were related to worse overall survival compared to those with low expression $(\mathrm{P}=$ 0.00076).
Over-expression and ablation of HOXB2 in GBM cell lines

We further studied the expression of HOXB2 in GBM cell lines. HEB is a normal brain cell line that we used to compare with five different GBM cell lines U251, U-87 MG, and GOS-3. A significant over-expression of HOXB2 was found in these three GBM cell lines compared to HEB cells. Furthermore, HOXB2 showed the highest expression in the U251 cell line while exhibited the lowest expression in the GOS-3 cell line compared to other GBM cells using mRNA levels for comparison (Figure 1a). Hence, in the following experiments, detection of the HOXB2 knockout effect was executed in the U251 cell line, and detection of the influences of HOXB2 over-expression was carried out in the GOS-3 cell line. The HOXB2 si RNA was transfected into the U251 cell line, and the non-specific sequence si-control was transfected as a control. After $48 \mathrm{~h}$ of transfection, the total RNA and protein were extracted and detected by qPCR and western blotting. The results indicated that si RNA- 1 and si RNA-2 could distinctly reduce HOXB2 expression both in mRNA and protein levels in U251 cells, and si RNA-2 displayed the lower expression of HOXB2. We utilized si-HOXB2\#2, and the knockout efficiency was over 80\% (Figure 1b-d). Furthermore, as illustrated in Figure 1e-g, pcDNA3.1-HOXB2 could remarkably elevate HOXB2 expression both at mRNA and protein levels in GOS-3 cells.

FIGURE 1. OVER-EXPRESSION AND KNOCKDOWN OF HOXB2 IN DIFFERENT GBM CELL LINES.

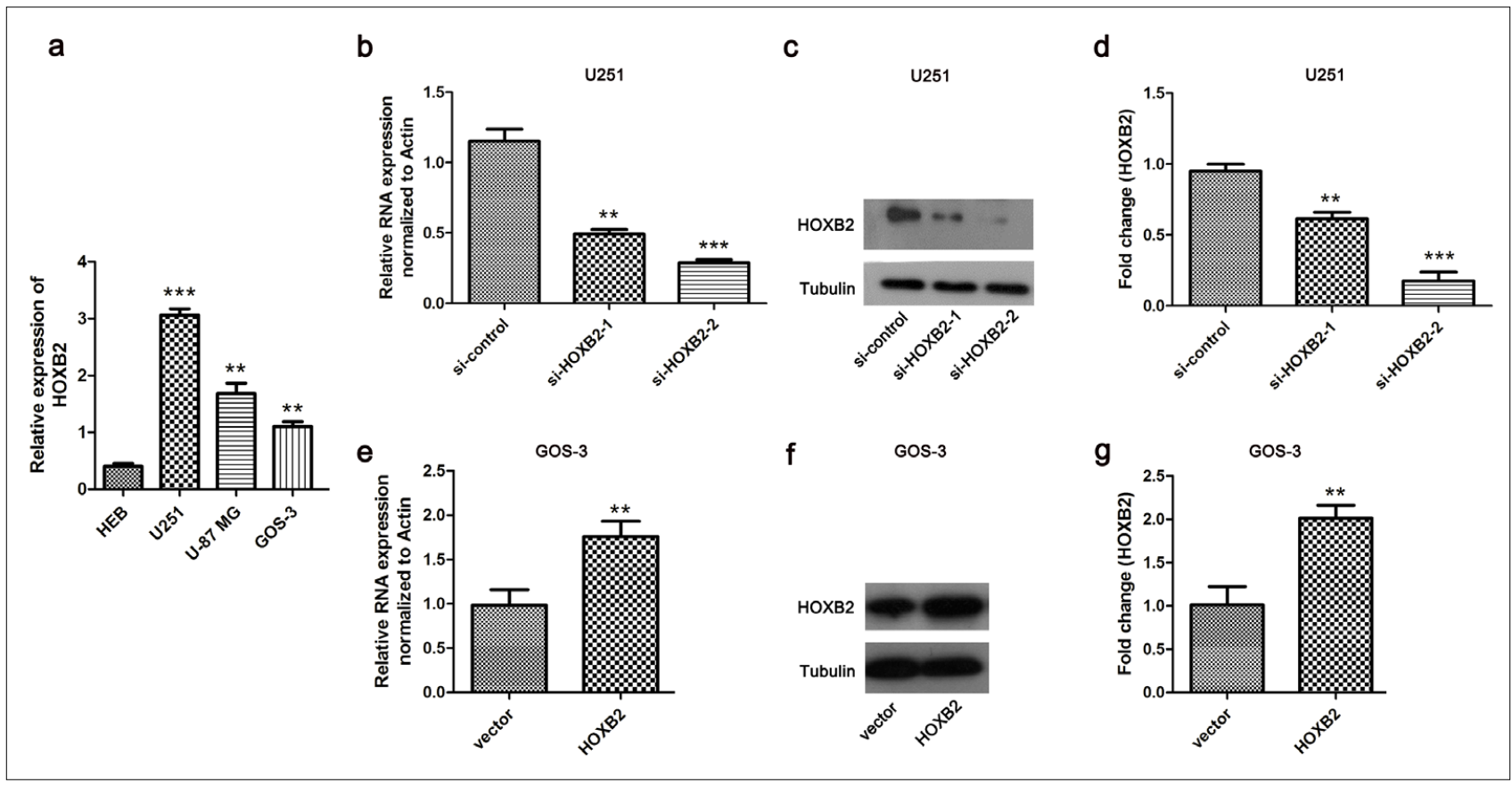


Knockdown of HOXB2 represses U251 cell proliferation, invasion and migration whilst HOXB2 high-expression accelerates GOS-3 cell proliferation, invasion, and migration

For the purpose of studying the impact of HOXB2 on GBM cell proliferation, CCK-8 assay was executed. As displayed in Figure 2a, the $\mathrm{OD}_{450}$ value of U251 cells was lower in the si-HOXB2 group compared to the si-control group, proving that HOXB2 deficiency reduced U251 cell proliferation $(\mathrm{P}<0.01, \mathrm{P}<0.01)$. The influences of HOXB2 on the invasion and migration of the U251 cells were investigated utilizing transwell assays. The silencing of HOXB2 visibly decreased the number of invasive and migrated crystal violet-stained cells in the transwell assay (Figure 2b-c). Conversely, the over-expression of HOXB2 sharply facilitated GOS-3 cell proliferation after being cultured for 48 $\mathrm{h}$ and $72 \mathrm{~h}$, but there was no significant effect at 24 $\mathrm{h}(\mathrm{P}<0.01, \mathrm{P}<0.01$, Figure 2d). Moreover, HOXB2 high-expression distinctly increased the number of crystal violet-stained GOS-3 cells in the transwell assay $(\mathrm{P}<0.01, \mathrm{P}<0.01$, Figure $2 \mathrm{e}-\mathrm{f})$.

Down-regulation of HOXB2 suppresses the $\mathrm{PI3K} / \mathrm{AKT}$ pathway in U251 cells, and over-expression of HOXB2 promotes the PI3K/AKT pathway in GOS-3 cells
The PI3K/AKT signaling pathway is an important signaling pathway in tumors. The western blot results indicated that the p-PI3K and p-AKT expression levels were decreased significantly in U251 cells transfected with si-HOXB2 compared to the si-control group (Figure 3a-b). Nevertheless, the protein levels of p-PI3K and p-AKT were remarkably improved by the over-expression of HOXB2 $(\mathrm{P}<0.01, \mathrm{P}<0.01$, Figure 3c-d).

\section{DISCUSSION}

In this paper, we discovered that HOXB2 high expression was linked to a poor prognosis of GBM patients. Furthermore, knockdown of HOXB2 significantly suppressed cell proliferation, invasion, and migration, possibly by activating the PI3K/AKT pathway in U251 cells.

Our results showed that si-HOXB2 overtly reduced the mRNA and protein expression levels of HOXB2 in U251 cells. HOXB2, as part of the HOX genes family, affects normal vertebrate organ and limb development $^{10}$. Recently, Hoxb2 was identified as a target gene of PLZF and may be associated with many developmental systems, such as hematopoiesis and the central nervous system (CNS) ${ }^{11}$. There is evidence to suggest that HOXB2 is expressed in the mature

FIGURE 2. HOXB2 DEPLETION RESTRAINED THE PROLIFERATION, MIGRATION, AND INVASION OF U251 CELLS, AND THE OVER-EXPRESSION OF HOXB2 ACCELERATES THE PROLIFERATION, MIGRATION, AND INVASION OF GOS-3 CELLS.

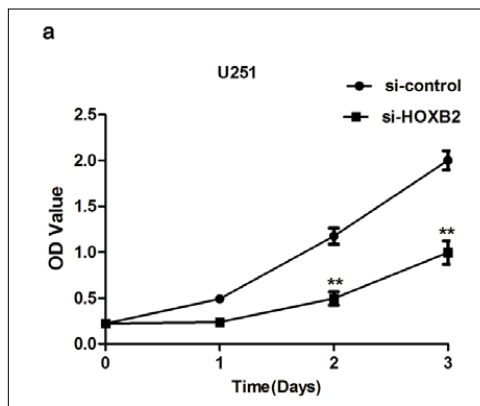

d

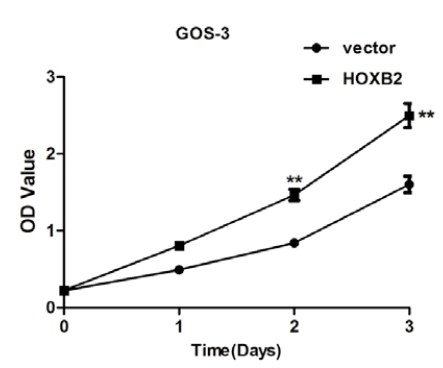

b
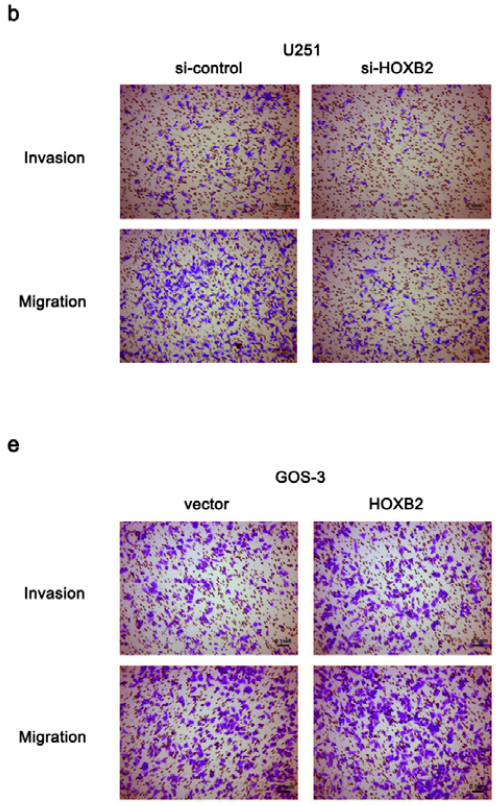

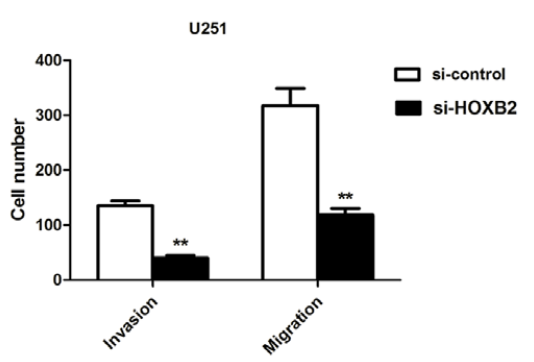

f

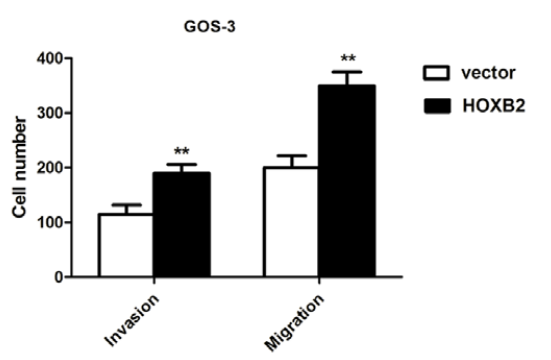


FIGURE 3. IMPACTS OF HOXB2 ON THE PI3K/AKT SIGNALING PATHWAY IN GBM CELLS.

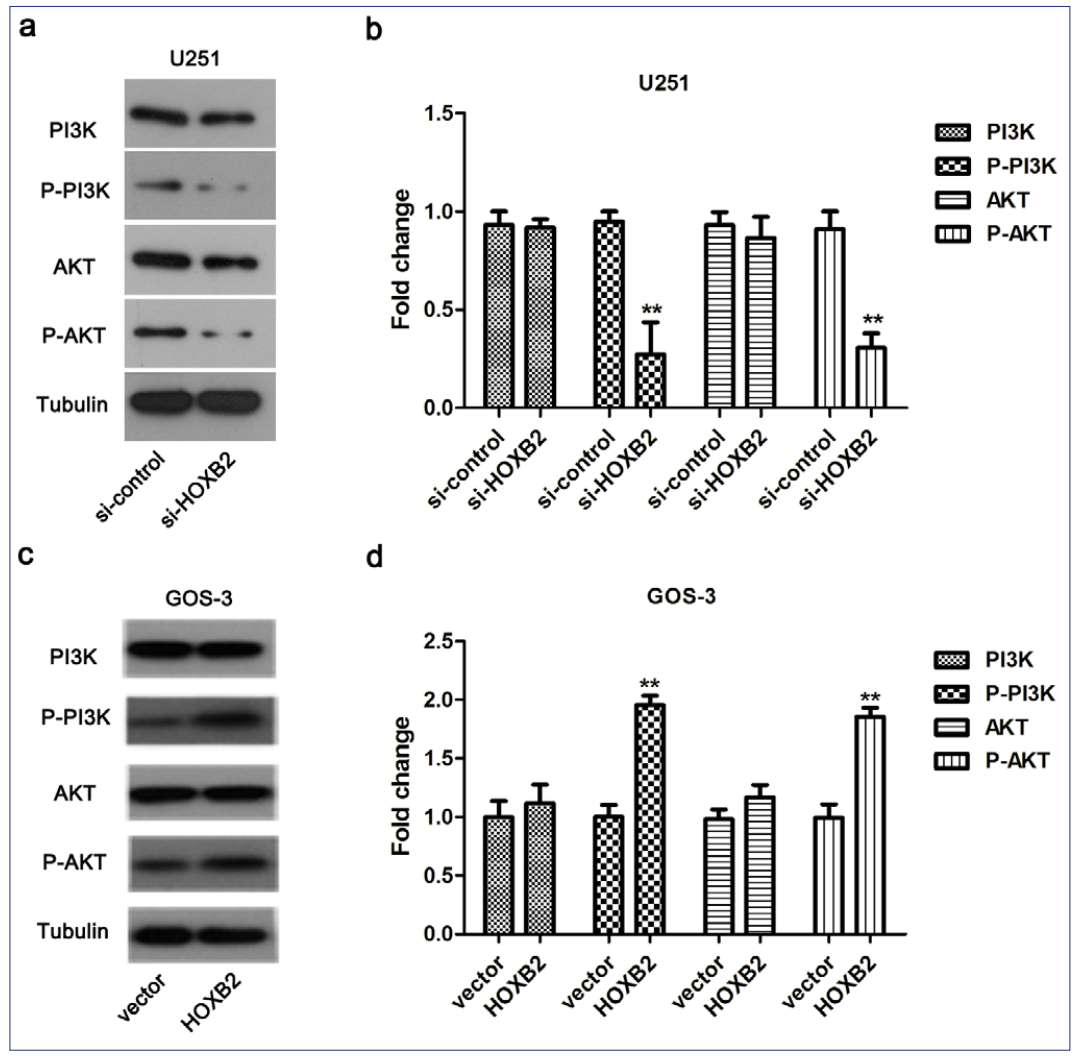

brain and is related to motor neurons in neuronal cell lines ${ }^{12}$. According to a recent report, HOXB2 and HOXB1 had genetic interaction during facial-nerve motor-nuclear development ${ }^{13}$. Boimel et al. ${ }^{14}$ hold the view that HOXB2 has a vital role in the regulation of breast cancer growth. It has been indicated that HOXB2 can be used as a novel biomarker for pancreatic cancer ${ }^{9}$. These data have motivated us to study whether HOXB2 has a role in GBM. In our study, we found that the down-regulation of HOXB2 suppressed the proliferation, invasion, and migration of U251 cells, manifesting that HOXB2 had a promoting role in GBM progression.

Studies have reported that the activation of PI3K/ AKT participated in the regulation of GBM proliferation $^{15}$. PI3K/AKT, as a significant signaling pathway in reacting to extracellular signals, can mediate many cellular processes including protein transcription, apoptosis, vascular metabolism, production, and cell viability $^{16,17}$. As a major downstream PI3K effector, AKT regulates the activity of many targets, including transcription factors, kinases, among others ${ }^{18}$. AKT participates in the modulation of cell proliferation and anti-apoptosis ${ }^{19,20}$.

\section{CONCLUSION}

In summary, the present research demonstrated that HOXB2 played a promoting role in GBM progression, partially through mediating the PI3K/AKT pathway. Thus HOXB2 may be a novel promising target for GBM treatment. A limitation of our study is the lack of in vivo experiments, which will be reported in future studies.

\section{Conflict of Interest}

The authors declare that they have no conflict of interests.

\section{Author Contributions}

All authors contributed to data analysis, drafting and revising the article, gave final approval of the version to be published, and agree to be accountable for all aspects of the work. 


\section{RESUMO}

OBJETIVOS: A HOXB2 é um novo indicador prognóstico para o câncer de pulmão. Mas não está claro se a HOXB2 tem algum efeito na progressão do glioblastoma (GBM). O objetivo deste artigo foi sondar as influências da HOXB2 na patogênese do GBM.

MÉTODOS: Foram analisados o nível de expressão e o poder prognóstico da HOXB2 em pacientes com GBM. Em seguida, os níveis de expressão proteica e mRNA da HOXB2 em linhagens de células de GBM foram testados por qRT-PCR e western blotting. A proliferação, a invasão e migração celular foram determinadas por CCK8 e ensaios transwell, várias vezes. Os níveis proteicos das proteínas associadas à via PI3K/AKT foram analisados pelo método western blotting.

RESULTADOS: Os resultados indicaram que havia uma clara superrexpressão da HOXB2 em pacientes com GBM e que a alta expressão da HOXB2 estava relacionada a um prognóstico negativo. Além disso, a expressão da HOXB2 foi mais elevada em todas as linhagens de células do GBM U251, U-87MG, GOS-3 do que nas células HEB (controle normal). Entretanto, a diminuição da expressão de P-PI3K e p-AKT foi identificada após a redução da expressão da HOXB2.

CONCLUSÕES: Esses dados demonstram que a HOXB2 desempenha um papel vital na progressão do GBM, podendo ser um alvo promissor para o tratamento do GBM.

PALAVRAS-CHAVE: Glioblastoma. Biomarcadores. Proteínas de homeodomínio.

\section{REFERENCES}

1. Carvalho JADV, Barbosa CCL, Feher O, Maldaun MVC, Camargo VP, Moraes FY, et al. Systemic dissemination of glioblastoma: literature review. Rev Assoc Med Bras. 2019;65(3):460-8.

2. Portela M, Segura-Collar B, Argudo I, Sáiz A, Gargini R, Sánchez-Gómez P, et al. Oncogenic dependence of glioma cells on kish/TMEM167A regulation of vesicular trafficking. Glia. 2019;67(2):404-17.

3. Cunha MLVD, Esmeraldo ACS, Henriques LAW, Santos Jr MAMD, Medeiros RTR, Botelho RV. Elderly patients with glioblastoma: the impact of surgical resection extent on survival. Rev Assoc Med Bras. 2019;65(7):937-45.

4. Fan Z, Zheng J, Xue Y, Liu X, Wang D, Yang C. NR2C2-uORF targeting UCA1miR-627-5p-NR2C2 feedback loop to regulate the malignant behaviors of glioma cells. Cell Death Dis. 2018;9(12):1165.

5. Song Y, Hu PJ, Dong YH, Zhang B, Ma J. Prevalence of reduced visual acuity among Chinese Han students in 2014. Beijing Da Xue Xue Bao Yi Xue Ban. 2017;49(3):433-8.

6. Lindblad O, Chougule RA, Moharram SA, Kabir NN, Sun J, Kazi JU, et al. The role of HOXB2 and HOXB3 in acute myeloid leukemia. Biochem Biophys Res Commun. 2015;467(4):742-7.

7. Miguez A, Ducret S, Di Meglio T, Parras C, Hmidan H, Haton C, et al. Opposing roles for Hoxa2 and Hoxb2 in hindbrain oligodendrocyte patterning. I Neurosci. 2012;32(48):17172-85

8. Xavier FC, Destro MF, Duarte CM, Nunes FD. Epigenetic repression of HOXB cluster in oral cancer cell lines. Arch Oral Biol. 2014;59(8):783-9.

9. Segara D, Biankin AV, Kench JG, Langusch CC, Dawson AC, Skalicky DA, et al. Expression of HOXB2, a retinoic acid signaling target in pancreatic cancer and pancreatic intraepithelial neoplasia. Clin Cancer Res. 2005;11(9):3587-96.

10. Bickelmann C, Frota-Lima GN, Triepel SK, Kawaguchi A, Schneider I, Fröbisch NB, et al. Noncanonical Hox, Etv4, and Gli3 gene activities give insight into unique limb patterning in salamanders. J Exp Zool B Mol Dev Evol. 2018;330(3):138-47.

11. Ivins S, Pemberton $K$, Guidez F, Howell L, Krumlauf R, Zelent A. Regulation of Hoxb2 by APL-associated PLZF protein. Oncogene. 2003;22(24):3685-97.

12. Zhai I, Lin H, Canete-Soler R, Schlaepfer WW. HoxB2 binds mutant SOD1 and is altered in transgenic model of ALS. Hum Mol Genet. 2005;14(18):2629-40.

13. Davenne M, Maconochie MK, Neun R, Pattyn A, Chambon P, Krumlauf R, et al. Hoxa2 and Hoxb2 control dorsoventral patterns of neuronal development in the rostral hindbrain. Neuron. 1999;22(4):677-91.

14. Boimel PJ, Cruz C, Segall JE. A functional in vivo screen for regulators of tumor progression identifies $\mathrm{HOXB2}$ as a regulator of tumor growth in breast cancer. Genomics. 2011;98(3):164-72.

15. Zhong C, Chen Y, Tao B, Peng L, Peng T, Yang X, et al. LIM and SH3 protein 1 regulates cell growth and chemosensitivity of human glioblastoma via the PI3K/AKT pathway. BMC Cancer. 2018;18(1):722.

16. Hemmings BA, Restuccia DF. The PI3K-PKB/Akt pathway. Cold Spring Harb Perspect Biol. 2015;7(4). pii: a026609. doi: 10.1101/cshperspect.a026609.

17. Gong H, Lü P, Zhang J, Li D, Zheng J, Song J. Na+/K+ATPase DR region-specific antibody protects $U 251$ cells against hypoxia reperfusion-induced injury via the PI3K/AKT and ERK pathways. Mol Med Rep. 2017;16(6):7901-6.

18. Manning BD, Toker A. AKT/PKB signaling: navigating the network. Cell. 2017;169(3):381-405.

19. Yang Y, Zhang $X$, Cui H, Zhang C, Zhu C, Li L. Apelin-13 protects the brain against ischemia/reperfusion injury through activating PI3K/Akt and ERK1/2 signaling pathways. Neurosci Lett. 2014;568:44-9.

20. Lee SG, Su ZZ, Emdad L, Sarkar D, Franke TF, Fisher PB, et al. Astrocyte elevated gene-1 activates cell survival pathways through PI3K-Akt signaling. Oncogene. 2008;27(8):1114-21. 